\title{
Futuristic Technologies in Asimov's Science Fiction Stories
}

Priyanka Kumari

Research Scholar

Department of English

Lalit Narayan Mithila University

Bihar, India

kumari.priyankaa19@gmail.com

\begin{abstract}
Isaac Asimov has advocated the idea that science fiction is a flavour that can be applied to any genre of fiction. The two novels that are used for this term paper; "The Naked Sun" and "The Robots of Dawn" are in keeping with this idea. The two stories are essentially whodunit stories, with several futuristic technologies like positronic robots and hyperspace travel blended into it. This term paper mainly focuses on identifying the futuristic technology in Isaac Asimov's science fiction stories. It would focus on how such futuristic technology stories, which take place in a world completely unfamiliar to the reader, fit into models of classification described by Tzvetan Todorov and Arthur Asa Berger. In this term paper, there would also be an attempt to do analyse how the notion of 'crime and punishment' is handled differently in these stories, and also to see how elements of science fiction and futuristic technologies fit into the genre of detective fiction. The term paper also contains a brief character analysis of the Futuristic technologies by detectives in the two stories.
\end{abstract}

Keywords: Science fiction, robots, futuristic, elements, detective 
Introduction:

Asimov is master in dealing with futuristic technologies in his works. The naked sun and the Robot of Dawn are depecting the technologies in his novels. He had created characters Elijah Baley and his partner Robot Daneel Olivaw as dectives who employe futuristic technologies to perform their task. The two novels are set in the same universe as Asimov's former short story series I, Robot, although the former is set in a period around two thousand years in the future. As Asimov writes in the introduction to The Naked Sun, it was his Horace Gold, the editor of Galaxy, who suggested Asimov to write a robot novel following the success of his short stories featuring positronic robots. Though Gold's original suggestion was to write a novel with a sociological theme, set in an overpopulated world in which robots were taking over jobs, Asimov was able to successfully merge this theme into a thriller futuristic technologies story. In the introduction to Asimov's Mysteries, he writes that science fiction shouldn't be classified as a member of the group of specialised literatures, but that it is a literary response to scientific change in which that "science fiction includes everything”. John Campbell, one of Asimov's first publishers, however, had told him that a science fiction mystery story was a contradiction in terms, and that advances in technologies could be used to get detectives out of their difficulties unfairly. As Asimov puts it well in the introduction to Asimov's Mysteries, “the detective could say, 'But as you know, Watson, ever since 2175, when all Spaniards learned to speak French, Spanish has been a dead language. How came Juan Lopez and to speak those significant words in Spanish!' Or else, he could have his detective whip out an odd device and say, 'As you know that Watson, my pocket-frannistan is perfectly efficent of detecting the hidden jewel in a juncture.' " But Asimov disputes that even ordinary mystery writers could be just as unfair to the readers, as they could voluntary hide a necessary cue or introduce characters from nowhere. So the same rules could be applied to science fiction mysteries: you don't invent new devices on the 
reader and solve the mystery with them, you don't take advantage of the future history and you carefully explain all facets of the future background well in advance. The fictional Futuractic technology should only make use of facts known to the reader. The two novels follows these rules really well and are excellent futuristic technologies stories that have elements of science fiction nicely blended into them.

Setting:

The two novels are set in a futuristic universe, two thousand years in the future. Advanced positronic robots are common and hyperspace travel has been invented, and with the help of these, humans have colonized fifty planets relative closer to the Earth (known as 'Spacer worlds'). By heavily depending on robot labor and controlling the human population, the Spacer worlds are rich and powerful compared to the overpopulated Earth where humans are prejudiced against the use of robots. The power disparity and differences in lifestyle between the Spacers and earthmen play a major role in all two novels.

"The Naked Sun" is set in the Spacer world of Solaria, that is very different from the futuristic Earth. The planet has a rigidly controlled population (of just twenty thousand compared to the Earth's 8 billion) and robots outnumber the humans ten thousand to one. Since there are so few people, most of the planet is just like open land, unlike the Earth where the Cities are closed spaces. The social setting is one in which humans strongly prefer to be alone, and all forms of human contact, except for holographic telepresence (an advanced method of video conferencing), are viewed as taboo. Due to this abhorrence to be in touch with other humans, and due to the very prosperous lifestyle, crime is virtual inconceivable of in Solaria; and the murder which Baley comes to investigation is the first crime ever to happen in the planet. The power disparity between Spacers and the Earth is clearly evident in this novel too, as can be seen in the Solarians' attitude towards Baley. This 
is simply due to the presence of Daneel who are from Aurora, Baily has some sort of recognition of authority in Solaria.

"The Robots of Dawn" is set in the spacer world of Aurora, which is interpreted as the first outer planet to be colonised by humans. It's also the most powerful (politically and economically) of all the Spacer worlds. The social setting of Aurora is in heavy contrast to that of Solaria. Unlike Solaria, where every kind of close human contact is viewed as a taboo, Aurorans keep a very liberal attitude towards sex; this contrast can be clearly seen through the words of Gladia, who was heretofore a Solarian. Aurora is not so much dependent on robots as Solaria, but it might be more advanced in the science of robotics than Solaria in which seeing as Solarians couldn't identify Daneel as a robot. Again, the power inequality between Aurora and Earth play an important role in this novel, since Baley is forced to conduct this investigation so as to save Earth from a hostile government coming to power in Aurora, which would prevent earthmen from expanding to more outer worlds in the galaxy.

Analysis of the Futuristic detectives:

Elijah Baley is a police Plainclothesman, his work for the New York City in the Police Department. Baley, like most earthmen in the futuristic world who feel agoraphobic, but he is shown as trying to overcome this shortcoming in "The Robots of Dawn". The agoraphobic nature of Baley mirrors Asimov's own personality, as Asimov himself was agoraphobic. Like Sherlock Holmes, he is represented as a pipe smoker. However, unlike Sherlock Holmes or Dupin, he isn't shown to have a deep passion for detective work, although this doesn't affect the quality of his work much. He does investigation strictly as a profession, and isn't really thrilled on being assigned to tough cases. He is reluctant to travel to outer worlds for investigation, and has to be forced to take up these cases. He is portrayed as being impatient and having a short temper; and this sometimes leads him to jump to 
conclusions and accuse people prematurely. In The Robots of Dawn, he accuses Amadiro, Gremionis and Vasilia; and this leads to him being nearly forced out of Aurora for committing slander. Despite these shortcomings, Baley proves to be an efficient detective by making crucial deductions at critical junctures. R Daneel Olivaw is a humaniform robot, built by Roj Sartan and Han Fastolfe, who are roboticists from Aurora. Being a robot, Daneel functions as an opposite to Baley's emotional nature. For assisting Baley in investigations, Daneel had been programmed with a sense of justice. Daneel functions according to the Three Laws of Robotics, and hence, by the First Law, acts in a protective way towards Baley even when Baley explicitly orders him not to (since the Second Law of following human orders is superseded by the First Law of preventing harm to humans). Daneel functions purely by logic, and this can be seen as advantageous sometimes (like when he, being unbiased, suspects Baley's wife or the fact that he is not annoyed by Baley's short temper or premature actions), but are disadvantageous at other times (for example, he doesn't share any sense of imagination and hence he is unable to think out of the box like Baley). Daneel, in The Caves of Steel, is said to have a minor telepathic ability, to read the emotional content of human thoughts, although unlike Giskard he doesn't have the ability to totally read minds.

Classification as thrillers:

Under Todorov's model, all two books could be classified as thrillers. In all two books, the detectives are vulnerable to physical harm and we can see the story of the crime overtaking the story of the investigation. In The Robots of Dawn, Baley is impressionable to probably bigger harm than he was in the previous two books. Though he rarely comes to physical harm, there's a constant pressure on him to successfully complete his investigation since otherwise he would be declassified in Earth (and in all two books there are hints that declassification is a very bad thing to happen to humans in the futuristic Cities of Earth). Not 
only is his personal reputation in harm, but there is also the harm that awaits Earth if $\mathrm{Dr}$ Fastolfe is convicted of roboticide. The earth-friendly humanists would lose power in the Auroran legislative and the powerful Spacer world of Aurora would be hostile to the Earth. Like in Solaria, in Aurora too Baley is nearly harmed by his exposure to the outside. When their car is damaged in the storm and R Giskard escapes with R Daneel, Baley nearly loses consciousness due to his exposure to the storm and the rain, and would probably have come to harm if Giskard hadn't found him. In this novel, unlike the previous two, Daneel also comes in the way of harm as he's nearly kidnapped while their car is deliberately damaged by Amadiro and chased by Amadiro's robots. In this book too, the story of the crime can be said to overtake the story of the investigation, as Giskard is deliberately sabotaging the investigation by reading and manipulating Baley's thoughts so that Baley's doubts about Giskard is removed. Under Arthur Asa Berger's model, Elijah Baley could be classified as the Procedural detective. He is an official member of the police force on Earth, and it's on the department's orders that he investigates all the crimes. In The Naked Sun, he is sent to Solaria by the Earth's police department, at the request of the Solarian government. Though he faces hostility initially, from the Solarians who are reluctant to see (as opposed to merely view) him and Agent Attlebish who wants him to return to Earth without completing the investigation, by convincing Agent Attlebish by using Daneel's perceived identity as a Spacer (no one in Solaria could figure out he is a robot), he is able to secure Attlebish's orders which helps him operate in his full authority as a policeman. His romantic life also becomes a part of this story as he develops a soft corner for the dead Spacer's wife, Gladia. In The Robots of Dawn, though he is again appointed to Aurora by the orders of the Earth's government, he has no official jurisdiction in Aurora. He was not brought there by the approval of the Auroran government, and he mostly functions like a private detective hired by Dr Fastolfe to establish his innocence. He often finds himself in conflict with the Auroran authorities like Amadiro 
and the Chairman, and is emotionally and morally committed to the happenings. Therefore, in this story, it would be more apt to classify him as a tough-guy detective rather than a procedural one.

Crime and Punishment:

There seems to be a very different notion of justice that prevails in all two novels. In neither of the three stories is the guilty person (or robot) actually punished; they are let go instead for 'greater goods'.

In The Naked Sun, it's clear to Baley that Gladia herself had physically committed the murder, since it was impossible for Leebig to actually approach another human being even if he intended to kill him. However, even after knowing this, he accuses Leebig of committing the murder, and as he explains it later on Earth, counted on the Solarians being too horrified at his misuse of robots to see through Baley's set up. He explains that he let her go since it was Leebig who had created the circumstances for the murder, by ordering the robot to hand over its arm to Gladia when she was angry, fully knowing that it would lead to Delmarre's murder, and that Gladia was merely an unwitting instrument of murder just as the robot . Baley says that he didn't care much about the Solarian law, that Earth's interests were pre-eminent. Hence stopping Leebig from his plans for building robot battleships was important. The Robots of Dawn is the very notion of crime with different. There's no human being who has come to harm, but a robot who has been rendered non-functional. Despite the robot being humaniform, it was still little more than robot damage. And since the robot belonged to the prime suspect Fastolfe, the crime was even less since it was his own property which he was being accused of damaging. The real objective here was saving Fastolfe's reputation and thus ensuring that Aurora had friendly relations with Earth so that they would help earthmen to colonise the space. Several times Baley attempts to come up with a story 
which he knows is false, but would convince the Aurorans that Fastolfe is innocent. Even in the end, he tries to portray Amadiro as the one who damaged Jander, even though Fastolfe had told him several times that Amadiro (or for that matter anyone other than Fastolfe himself) would find it impossible to commit that crime. In the end, though he finds out that Giskard was the one responsible for the crime, Baley doesn't reveal this information to the public. Since the real purpose of his visit to Aurora is accomplished, he probably found it unnecessary to expose Giskard; or, as Giskard said he could do later, his mind was probably manipulated by Giskard in such a way that he would never find the urge to talk about Giskard's involvement in the crime, even though he would always remember it.

Blending of science fiction with futuristic detective fiction:

As mentioned in the introduction, Asimov was told that science fiction mysteries would not play fair with the reader. To prevent this 'potential cheating of the readers', Asimov proposed the following rules (in the introduction to Asimov's Mysteries); that the writer shouldn't spring new devices on the reader and solve the mystery with them and that the writer shouldn't take advantage of future history to introduce ad hoc phenomena. All facets of the future background should be explained well in advance so that the reader gets a decent chance to see the solution. The detective should make use of only the facts which are known to the reader in the present, or the 'facts' of the fictional future which are explained beforehand. Asimov says that if these rules are accepted, it becomes obvious that science fiction mystery is a thoroughly acceptable literary form. These rules can be compared to Van Dine's Twenty rules for detective fiction. It can be seen that the rules laid about by Asimov cover the first rule of Van Dine, i.e., the reader must have equal opportunity with the detective for solving the mystery and that all clues must be plainly stated and described. The comparison of these rules with Van Dine's 14th rule can be interesting. The 14th rule states 
that the methods must be rational and scientific and there should be no use of pseudo science. This rule can be interpreted in a different ways in science fiction, since, as Arthur C Clarke says, "any sufficiently advanced technology is indistinguishable from magic". Therefore, this rule can be modified as "the methods must be within the domain of what is rational and scientific in the fictional universe, as explained by the author'. Such a modification allows these rules to cover Van Dine's 14th rule as well. The most important futuristic technology in all three novels is the positronic robots. In The Caves of Steel, a robot is a main instrument in executing the crime and another robot was the intended victim of the crime. In The Naked Sun and The Robots of Dawn, robots are more actively involved in the crime, especially in The Robots of Dawn in which both the victim and the culprit are robots. In these two novels, Asimov's famous three laws of robotics play a major role.

The three laws are as follows:

1. A robot may not harm a human being or, through inaction, allow a human being to come to harm. 2. A robot must obey the orders given to it by human beings, except where such orders would conflict with the First Law. A robot must obey the commands given by humans except that such orders would conflict with the first law 3. A robot may not injure its own kind and should defend its own kind unless it is interfering with the first or second rule. Asimov's robots follow all these rules through all these books, and the writer has made sure that he doesn't invent or break a law out of the blue to use as a plot device. In The Caves of Steel, Baley suspects Daneel to have been built without the First Law, but is proven wrong by the expert roboticist he had called. However, all three books involve the robots bending the law and people finding loopholes in the law to use robots to harm other people. This doesn't really break the rule of not inventing facts to solve the mystery, since even a reader could have arrived at this solution using the facts presented to them. Through various instances, it had been shown to the readers that a human being can cleverly issue orders to manipulate a 
robot, and Asimov only uses these facts to solve the mysteries. In The Naked Sun, there are several instances where people work around the First Law - when Agent Gruer is poisoned, when Baley is shot at with a poisonous arrow and as we find out in the end, to provide the weapon to murder Delmarre. In all cases, robots unwittingly follow the orders of a human being without knowing that they are helping them commit a murder. In The Robots of Dawn, Asimov comes close to breaking this rule. The plot heavily relies on applications of the Laws of Robotics, and in the end the mystery is solved by attributing to R Giskard the ability to read and manipulate human (and robot) thoughts. But this too was a 'fact' that was once explained to the readers, when earlier in the novel Fastolfe narrates the legend of Susan Calvin's telepathic robot, to show how a robot could be potentially damaged by a paradox in the laws of robotics. There are also a number of other instances in the novel, like when Giskard gets to Baley before Daneel to save him, which show that Giskard might have skills that might not be obvious to the rest of the characters. Various other futuristic technologies too are used in the novel, such as hyperspace travel, expressways, psychic probes, cars that 'fly', the futuristic Cities (the 'caves of steel') etc. Other than the Cities, the others seldom affect the elements of detective fiction in the novel; they merely act as plot devices to make the stories more fun and entertaining.

\section{Conclusion:}

These novels are set in the futuristic earth, which is overpopulated and can be thought of as a depressing world. Robots are shown to be slowly taking over the less worldly jobs and a large number of people are versus robots taking over their jobs. The crime occurs in spacetown, a colony of spacers in earth just outside New Yark City. Robots live in spacetown are much more avant garde than the ones in earth. Thus this paper tries to analyse 
how to the two novels follow these rules really well and are excellent futuristic technology stories that have elements of science fiction nicely blended into them. 


\section{References}

Isaac Asimov, The Naked Sun, Doubleday, January 1957

The Robots of Dawn, Doubleday, 1983

, Asimov' Mysteries, Doubleday,1968

http://en.wikipedia.org/wiki/The_Naked_Sun, Pages-187, Retrieved January 4,2020.

http://en.wikipedia.org/wiki/The_Robots_of_Dawn, Retrieved March 8, 2020.

http://en.wikipedia.org/wiki/Isaac_Asimov, Retrieved Dec. 30, 2019.

http://en.wikipedia.org/wiki/R._Daneel_Olivaw, Retrieved Feb. 27,2020.

http://www.victorianweb.org/genre/PIlit.html,Retrieved Jan. 30,2020.

http://www.museum.tv/eotv/genre.htm,Retrieved Feb.1,2020.

http://gaslight.mtroyal.ca/vandine.htm, Retrieve on Dec.17,2019.

http://en.wikipedia.org/wiki/Clarke's_three_laws, Retrieve on Jan.3,2020 